Claudia de Lima Costa Universidade Federal de Santa Catarina, Florianópolis, Brasil

Susana Bornéo Funck Universidade Federal de Santa Catarina, Florianópolis, Brasil

\title{
O Antropoceno, o pós-humano e o novo materialismo: intervenções feministas
}

Esta obra está sob licença Creative Commons.
Podemos dizer que já é consenso na comunidade científica que as mudanças climáticas se tornaram uma das maiores ameaças à vida no nosso planeta. Falar sobre mudanças climáticas, por sua vez, é invocar os acalorados debates sobre o Antropoceno. O termo faz referência a uma nova era geológica, quando os seres humanos se tornaram uma força não apenas biológica, mas, sobretudo, geológica. Segundo Dipesh CHAKRABARTY (2013), os fatores antropogênicos que contribuem para o aquecimento global - como, por exemplo, a queima de combustíveis fósseis, a industrialização de animais, o desmatamento das florestas tropicais, juntamente com o desdobramento do capitalismo no Ocidente - inauguraram a era do Antropoceno. Donna J. HARAWAY (2016a) preferiu rotular esta época de Capitaloceno e, mais recentemente, Chthulucene (2016b).

Seja qual for o termo escolhido para definir o tempo geológico atual, um dos efeitos do Antropoceno foi o de entremear as cronologias humanas e não humanas. Como argumenta Chakrabarty (2013), o tempo humano e o tempo da natureza, assim intercalados, transformam a maneira de os apreendermos: precisamos de novas abordagens epistemológicas que foquem os seres humanos como espécies entre espécies, frisando a "interrelacionalidade das formas de vida" (p. 19). Porém, é esta nossa dificuldade:

Nós, humanos, nunca nos experimentamos como espécie. Podemos apenas compreender intelectualmente ou inferir a existência da espécie humana, mas nunca experimentá-la como tal. Não poderia haver 
nenhuma fenomenologia de nós mesmos como espécie. Mesmo se nós nos identificássemos emocionalmente com uma palavra como humanidade, não saberíamos o que é ser uma espécie, pois, na história das espécies, os humanos são apenas um exemplar do conceito espécie, como, com efeito, seria qualquer outra forma de vida. Mas ninguém experimenta a condição de ser um conceito (p. 21).

Dizer isto, no entanto, não é novidade para muitas teóricas feministas como Donna Haraway, Susan Hekman, Stacy Alaimo, Karen Barad e outras que, atuando nas ciências ditas exatas, escrevem sobre o (re)retorno da matéria na teoria social (vitalismo crítico) e exploram as múltiplas dimensões desse pensar como espécie (species-thinking). Estamos sempre já emaranhadas com outras espécies/materialidades (como nos lembra Haraway, somos multiespécies). O "pensar como espécie" inaugura outro tipo de racionalidade ou, se quiser, episteme. Ao contrário da racionalidade ocidental tradicional e dos paradigmas representacionais (nos quais há uma separação entre nossa experiência do mundo, o mundo em si e o conhecimento do mundo), trata-se de um refletir sobre nossas conexões parciais com materialidades humanas e não humanas. É um pensar corporificado e relacional, já que os conceitos e as abstrações resultantes do processo de conhecimento não constituem um mundo separado da matéria e das coisas. Para conhecer, precisamos estar imersas na matéria e no mundo através de um contínuo engajamento. Species-thinking e o vitalismo crítico que informa o novo materialismo apontam para a necessidade de se efetuar um deslocamento político e epistemológico do humano (e da racionalidade eurocêntrica) para o pós-humano. Como dizia Stuart Hall, momentos políticos produzem movimentos teóricos. Essas abordagens teóricas inovadoras também convocam uma mudança ontológica, isto é, um deslocamento do ponto de vista de que há diferentes perspectivas sobre uma realidade objetiva e universal para um reconhecimento de múltiplos mundos/realidades. A virada ontológica efetua um movimento em direção às coisas, aos corpos, aos organismos, a qual não reduz o processo cognitivo apenas aos seres humanos. Enfim, estamos diante de uma ecologia de saberes e de cosmopolíticas que prometem revolucionar as teorias feministas, os campos disciplinares e, principalmente, os limites da perversa dicotomia do humano e não humano, instituidora da modernidade ocidental e constitutiva da colonialidade do poder.

Os trabalhos aqui publicados exploram diferentes aspectos desse novo panorama epistemológico. $\mathrm{O}$ artigo de Stacy Alaimo, que serve de introdução e "provocação" ao presente debate, foi publicado inicialmente como 
introdução ao livro Material Feminisms, de 2007, e, nesse sentido, é instrumental para que se discuta o surgimento de novos e importantes conceitos que vêm alterando a teoria e a política feministas nestas décadas iniciais do século XXI.

Segundo Alaimo, a questão do corpo, que já foi vista como problemática para as mulheres ao essencializar a "natureza feminina" e distanciá-la da cultura, precisa ser repensada num contexto menos polarizado e mais amplo. Para ela, como para várias das autoras incluídas em sua coletânea, é preciso olhar para as relações entre a corporalidade humana e a natureza mais-que-humana, ou "ambiente", contato esse que possibilita novos posicionamentos éticos e políticos, já que a natureza deixa de ser vista como um mero pano de fundo para as aventuras do humano.

Essa consequente valorização da natureza, ao erradicar sua associação tradicional com falta de intelecto e passividade, poderá levar ao apagamento dos dualismos marcados pelo gênero (natureza / cultura, corpo / mente, objeto / sujeito, recurso / agenciamento, e outros) que contribuem para silenciar e diminuir certos grupos humanos e a vida não humana. Mas um dos problemas daí resultantes é a necessidade de entender a possibilidade de agência para além dos limites do humano, questão sobre a qual várias teóricas têm se debruçado. Para Carolyn MERCHANT (1989), por exemplo, a natureza deve ser vista como um ator social; para Ladelle McWHORTER (1999), ela deve ser considerada uma agência sem agentes, um constante tornar-se sem intenção ou vontade.

No entanto, como pontua Alaimo, torna-se difícil repensar a materialidade de modo tão radical no contexto teórico atual, voltado tão completamente para o discursivo. Segundo ela, os feminismos materialistas, com sua noção de transcorporalidade, ao contrário dos estudos da corporalidade humana de orientação discursiva, ampliam a questão do humano, colocando-a num tempo-espaço epistemológico no qual, "por estarem sempre agindo e sofrendo ações, corpos humanos e naturezas não-humanas se transformam, desdobram e, assim, resistem à categorização, conhecimento absoluto, e controle".

A dimensão política dessas novas noções e dos novos feminismos materialistas em geral é a preocupação central do ensaio de Hanna Meissner, incluído a seguir. Partindo de uma crítica ao antropocentrismo, a autora define política como uma ação de seres humanos que se esforçam para transformar as condições em que vivem, condições essas percebidas como intrinsecamente sociais. No entanto, argumenta ela, há, nessa noção de política, uma falta de atenção à agência e à historicidade do material, vinculação que os novos materialismos procuram articular. 
Rechaçando, em certa medida, a crítica que Karen BARAD (2007) faz a Judith BUTLER (2011) e à primazia do discurso, Meissner argumenta que, embora Butler esteja realmente interessada na agência constitutiva da linguagem, ela não nega a possibilidade de outras agências, inclusive das agências corporais e psíquicas do insólito, daquilo que está excluído da ordem da inteligibilidade. No entanto, retoma de Barad a noção de responsabilidade como mandamento ético de desenvolver a capacidade de responder ao "outro" por meio de uma solidariedade que não se baseia apenas em proximidade ou semelhança, mas no fato de que estamos todos/as envolvidos/as numa mesma situação.

Esse envolvimento, da perspectiva do século XXI, inclui, ainda, a impossibilidade de separar seres humanos de seu entorno não humano. Da mesma forma que Alaimo, enfatiza que o reconhecimento de uma dependência constitutiva com outros humanos e mais-que-humanos nos obriga a reconceitualizar o que entendemos por agência e a questionar radicalmente quem somos e o que podemos ser como sujeitos humanos, ou seja, a própria política como a entendemos.

Ampliando o debate para questões da espécie humana em sua relação com o mundo material, o artigo de Melina Savi apresenta e discute o conceito de Antropoceno, era geológica na qual as mudanças causadas por ações humanas são tão intensas e generalizadas, que o ser humano passa a constituir uma força geológica, com consequências extremas para o planeta. Após historicizar o surgimento e a utilização do termo, volta-se para a questão da responsabilidade ética, já abordada nos artigos anteriores. Enfatizando a mudança climática no contexto do ecofeminismo, Savi reconhece, com base em Richard GRUSIN (2015), a "virada não-humana" como forma de descentralizar o humano em favor do não humano, entendido em termos de "animais, afetividade, corpos, sistemas orgânicos e geofísicos, materialidade, ou tecnologia".

Voltando-se para a área das humanidades e, especialmente, da literatura (fantasia e ficção científica), examina a contribuição de obras como The Stone Gods (2007), de Jeanette Winterson, The MaddAddam Trilogy (Oryx and Crake, 2004; The Year of the Flood, 2009; e MaddAddam, 2014), de Margaret Atwood, e Station Eleven (2015), de Emily St. John Mandels, para a formação de uma consciência feminista, ecocrítica e multiespécies. Ao quebrarem representações tradicionais e hegemônicas das relações inter- e intraespécies, tais narrativas contribuem para a mudança de paradigmas e epistemologias amplamente discutida nos artigos de Alaimo, Brandão e Meissner. 
Essas e outras importantes questões, em especial as levantadas por Stacy Alaimo, são retomadas e cuidadosamente analisadas no artigo de Izabel Brandão. Além de uma relevante apresentação de Alaimo no âmbito da pesquisa feminista, Brandão discute a relação entre ecocrítica feminista ou ecofeminismo, e justiça ambiental ou feminismo material, com os quais Alaimo se alinha, ressaltando as confluências entre esses campos teóricos.

Após identificar os eixos centrais do artigo provocador das discussões aqui apresentadas (A teoria feminista e seu afastamento da natureza; A virada material na teoria feminista; Agência sem sujeitos; Um pouco fora de alcance: o espaço epistemológico como espaço ético; Mapas de trânsito e O tempo-espaço trans-corpóreo e os corpos tóxicos), Brandão os contextualiza no cenário mais amplo das discussões atuais, ampliando sua relação com pensadoras contemporâneas e com o próprio pensamento de Alaimo em artigos anteriores. É importante ressaltar, também, as relações estabelecidas com traduções disponíveis no Brasil, onde o materialismo feminista e a justiça ambiental vêm ganhando espaço e desencadeando debates. Inclusive, ao discutir a complexa questão da natureza como agente (ou re-agente), Brandão tece paralelos com o recente desastre ambiental ocorrido em Minas Gerais, em novembro de 2015. Como um todo, os comentários apresentados nesse último artigo da seção ampliam e aprofundam as ideias, conceitos e epistemologias dos artigos anteriores.

\section{Referências}

BARAD, Karen. Meeting the Universe Halfway: Quantum Physics and the Entanglement of Matter and Meaning. Durham: Duke University Press, 2007.

BUTLER, Judith. Bodies That Matter: On the Discursive Limits of 'Sex'. New York: Routledge, 2011.

CHAKRABARTY, Dipesh. "O clima da história: quatro teses". Sopro, n. 91, p. 4-22, 2013.

GRUSIN, Richard. "Introduction". In: ___ (Ed.). The Nonhuman Turn. Minneapolis: University of Minnesota Press, 2015. [versão e-book]

HARAWAY, Donna J. "Staying with the Trouble: Anthropocene, Capitalocene, Chthulucene". In: MOORE, Jason W. (Ed.). Anthropocene or Capitalocene: Nature, History and the Crisis of Capitalism. Oakland: PM Press, 2016a. p. 34-76. Staying with the Problem: Making Kin in the Chthulucene. Durham: Duke University Press, $2016 \mathrm{~b}$.

McWHORTER, Ladelle. Bodies and Pleasures: Foucault and the Politics of Sexual Normalization. Bloomington: Indiana University Press, 1999. 
MERCHANT, Carolyn. Ecological Revolutions: Nature, Gender, and Science in New England. Chapel Hill: University of North Carolina Press, 1989.

[Recebido em 01/08/2016 e aprovado em 12/01/2017]

Claudia de Lima Costa (clcosta@floripa.com.br) é professora associada de Teoria Literária na Universidade Federal de Santa Catarina. Possui graduação em Filosofia e Teorias da Comunicação - Michigan State University (1985), mestrado em Teorias da Comunicação - Michigan State University (1987) e doutorado em Cultural Studies - University of Illinois em Urbana (1998). Foi professora visitante na University of California, Santa Cruz (EUA) e na University of Massachusetts, Amherst (EUA), onde lecionou disciplinas nos respectivos departamentos de Feminist Studies e Women, Gender and Sexuality Studies. Realizou pósdoutoramento na University of California, Santa Cruz, e na University of Massachusetts, Amherst. Foi vice-presidente e presidente da seção Cultura, Política e Poder da Associação de Estudos Latino-Americanos (LASA), na qual também exerceu várias outras atividades em comitês julgadores específicos. Coorganizou o livro Translocalities / Translocalidades: feminist politics of translation in the Latin/a Américas (Duke University Press, 2014) e está coorganizando o livro Traduções da cultura: perspectivas críticas feministas (1970-2010). Atualmente, é bolsista de produtividade em pesquisa do CNPq e atua na área de Letras, com ênfase na interseção entre as teorias feministas, tradução cultural e as teorias pós-coloniais e descoloniais nas Américas.

Susana Bornéo Funck (sbfunck@gmail.com) tem bacharelado em Inglês pelo Mount Holyoke College, Estados Unidos, é tradutora-intérprete pela PUCRS, mestra em Inglês e doutora em Humanidades pela Universidade do Texas, em Arlington. Realizou pesquisa de pós-doutorado na Brown University. Foi professora de literaturas de língua inglesa na UFSC e de Estudos do Discurso na UCPEL. Aposentada desde 2014, continua atuando na Revista Estudos Feministas e no Instituto de Estudos de Gênero da Universidade Federal de Santa Catarina (UFSC). 